\title{
Qualidade do trabalho no setor TIC na Argentina: tensões entre trajetórias individuais e coletivas*
}

\author{
Andrea Pujol ${ }^{1}$ \\ Universidade Nacional de Córdoba (Córdoba, Argentina)
}

\begin{abstract}
No estudo que inspirou este artigo, procurou-se enriquecer os trabalhos clássicos sobre qualidade do emprego, que limitam sua aproximação às variáveis institucionais. Dessa maneira, tentou-se incluir dimensões que permitam considerar a qualidade de trabalho percebida subjetivamente pelos trabalhadores. A organização do trabalho e a mediação do coletivo representam a chave na configuração de um trabalho de qualidade. No setor informático, a organização por objetivos exige que os funcionários cumpram tarefas que envolvem aprendizagem contínua e favorecem a autonomia. Em compensação, as exigências cognitivas são muito elevadas, a duração da jornada de trabalho é desregulamentada, sem limite de tempo, estendendo-se além do local de trabalho. Consequentemente, os postos de trabalho inscrevem-se em condições ergonômicas não controladas. Essa organização do trabalho prejudica os trabalhadores e impede a construção de um coletivo de trabalho capaz de defender seus interesses.
\end{abstract}

Palavras-chave: Qualidade do emprego, Organização do trabalho, Subjetividade, Clínica do trabalho, Setor IT.

La calidad del trabajo en el sector TIC en Argentina: tensiones entre trayectorias singulares y colectivas

En el estudio que inspiró este artículo, se ha buscado enriquecer los trabajos clásicos sobre calidad del empleo, que limitan su aproximación a las variables institucionales, para incluir dimensiones que permiten considerar la calidad de trabajo percibida subjetivamente por los trabajadores. La organización del trabajo y la mediación del colectivo juegan un rol clave en la configuración de un trabajo de calidad. En el sector informático, la organización por objetivos exige a los empleados cumplir tareas que implican aprendizaje continuo y que favorezcan la autonomía. En contrapartida, las exigencias cognitivas son muy elevadas, la duración de la jornada de trabajo se encuentra desregulada, sin límite de tiempo, y se extiende hacia más allá del lugar de trabajo por lo cual los puestos de trabajo se inscriben en condiciones ergonómicas no controladas. Esta organización del trabajo afecta a los trabajadores y bloquea la construcción de un colectivo de trabajo capaz de defender sus intereses.

Palabras clave: Calidad del empleo, Organización del trabajo, Subjetividad, Clínica del trabajo, Sector IT.

La qualité du travail dans le secteur des TIC en Argentine: tensions entre trajectoires singulières et collectives

Dans l'étude qu'inspire cet article, on a cherché à enrichir les travaux classiques sur la qualité des emplois qui limitent leur approche aux variables institutionnelles pour inclure des dimensions qui permettent de considérer la qualité du travail telle que subjectivement perçue par les travailleurs. L'organisation du travail et la médiation du collectif jouent un rôle clé dans la configuration d'un travail de qualité. Dans le secteur informatique, l'organisation par objectifs exige aux employés d'accomplir des tâches qui encouragent l'apprentissage continu et favorisent leur autonomie. Par contre, les exigences cognitives sont très élevées, la durée de la journée de travail est déréglementée, sans limite de temps, et s'étend en dehors du lieu de travail et les postes s'inscrivent dans des conditions ergonomiques non contrôlées. Cette organisation du travail affecte les travailleurs et empêche la consolidation d'un collectif de travail capable d'agir pour la défense de leurs intérêts.

Mots-clés: Qualité de l’emploi, Organisation du travail, Subjectivité, Clinique du travail, Secteur TI.

The quality of work in the IT sector in Argentina: tensions between singular and collective trajectories

In the study that inspired this article, we try to enrich the classic work on the quality of jobs that limits its focus to institutional variables to include dimensions that allow to take into account the quality of work subjectively perceived by workers. Work organization and collective mediation play a key role in creating quality work. In the IT sector, the organizing objectives required of employees performing tasks that encourage learning and promote selfsufficiency. The cognitive demands are very high, the configuration of the workday deregulated, no time limit, takes place outside of work and, consequently, the ergonomics are not controlled. This organization of work affects workers and prevents the consolidation of a group capable of operating in defense of their interests.

Keywords: Quality of employment, Work organization, Subjectivity, Clinical work, IT Sector.

\footnotetext{
* Publicado originalmente em: Nouvelle Revue de Psychosociologie, 15 (1), 131-144, 2013. DOI: 10.3917/nrp.015.0131

1 Professora titular da Cátedra de Psicologia Laboral da Faculdade de Psicologia da Universidade Nacional de Córdoba.
} 


\section{Introdução}

$\mathrm{P}$ ara dar conta da questão da qualidade do emprego, partindo das contribuições dos estudos clássicos (Slaughter, 1998; Infante \& Vega Centeno, 1999; Valenzuela \& Reinecke, 2000; Vanbastelaer \& Hussmann, 2000), é preciso considerar simultaneamente os aumentos de salário, a segurança no trabalho, a duração e a intensidade da jornada de trabalho, as possibilidades de encargos sociais, de formação etc. Cada um dos autores tem desenvolvido um amplo repertório de indicadores associados a essas dimensões. No entanto, também é necessário levar em conta certas características do trabalho que permitem dar uma resposta às expectativas econômicas, sociais, psicológicas e físicas dos trabalhadores. Nessa perspectiva, a noção de qualidade do emprego exclui não apenas esses benefícios, mas também outras dimensões igualmente relevantes: a organização do trabalho que valoriza as competências dos trabalhadores e os recursos e processos que possibilitam o enriquecimento contínuo das capacidades dos sujeitos, aos quais podemos denominar processos de formação sistêmica (Bisang et al., 2005).

É importante questionar a pertinência da noção de emprego antes de abordar a complexidade do problema da qualidade, bem como considerar o "trabalho" como uma categoria mais apropriada para explorar as diferentes dimensões da experiência dos sujeitos no trabalho. Assim, é imprescindível ultrapassar a questão dos contratos e das condições institucionais, com o intuito de integrar a problemática da organização do trabalho: esta pode favorecer o desenvolvimento, a expressão da criatividade e a inovação, mas pode também representar uma pressão sobre os processos de subjetivação.

A qualidade do emprego envolve dimensões objetivas e subjetivas. Algumas delas se referem às relações de trabalho, outras são próprias da organização concreta das atividades e das significações que a organização do trabalho permite construir. Os trabalhadores são capazes de avaliar essas dimensões, tanto as mais objetivas quanto aquelas relacionadas às expectativas pessoais ou à vida coletiva em seu meio de trabalho. Neste artigo, esforçamo-nos em mostrar que "o trabalho", do ponto de vista dos trabalhadores, é a via privilegiada para compreender o problema da qualidade do emprego.

Trata-se, então, de estabelecer as relações existentes entre a qualidade do emprego, a qualidade do trabalho e a qualidade das condições do posto de trabalho (Barros \& Mendoza, 1999; Farné, 2003; Infante \& Vega Centeno, 1999; Mocelin, 2008). Também é preciso considerar outras dimensões que explicam a relação entre trabalho e subjetividade em termos de qualidade da experiência de trabalho. Isso deve permitir uma melhor compreensão das contradições entre trajetórias individuais e trajetórias coletivas dos trabalhadores e considerar como o prazer e o sofrimento inerentes ao trabalho remetem a trajetórias singulares e a grupos concretos.

A percepção da insegurança e da precariedade do trabalho é relativamente independente dos índices estatísticos. Portanto, é essencial explorar o sentido e o valor que os empregados outorgam à qualidade do emprego em função das características da relação de trabalho, além de avaliar a natureza da organização das atividades e seus efeitos sobre o desenvolvimento e a saúde.

Do ponto de vista teórico, partiremos de uma crítica ao trabalho contemporâneo para mergulhar na dimensão subjetiva da atividade, no campo de contradições em que ela se desenvolve. Inscrevemo-nos, dessa maneira, na perspectiva psicossociológica, como quadro de análise das articulações entre trabalho e subjetividade. A psicossociologia procura dar conta das tensões entre a vida psíquica e o campo social, e vem contribuindo para a compreensão dos processos de construção social da subjetividade nos novos contextos de trabalho. Nesse quadro, ela oferece um olhar sensível para às transformações sócio-históricas e institucionais, ao mesmo tempo que esclarece o papel que os grupos e as organizações exercem na dinâmica do trabalho. 
Baseados nos trabalhos de Curie (2005) e Clot (2008a), propomos observar o trabalho como um processo complexo em que se combinam três níveis de análise: as condições de trabalho, a atividade de trabalho e os afetos no trabalho, sem reduzir a atividade de trabalho nem a suas condições internas (aptidões dos trabalhadores), nem a suas condições externas (tarefas prescritas). Desse ponto de vista, questionamos tanto o postulado psicologista, que reduz a análise do trabalho às características individuais dos assalariados, quanto as proposições objetivistas, que consideram os trabalhadores como simples "recursos" da gestão, no mesmo nível que os recursos financeiros. No primeiro caso, a potência e o poder de agir são atribuídos apenas ao sujeito, considerado responsável por tudo que acontece, inclusive falhas, erros ou omissões. No segundo caso, o sujeito é apagado, torna-se invisível, e apenas se levam em conta as prescrições e o controle do processo de trabalho.

O trabalho é sempre situado num contexto histórico e social particular. Ele é também uma construção coletiva que é possibilitada pela mediação da linguagem. A incidência da dimensão sócio-histórica e institucional do trabalho nas experiências subjetivas dos trabalhadores produz temporalidades partilhadas. Estas deixam também suas marcas nas trajetórias individuais, com suas implicações identitárias.

\section{Uma clínica do trabalho: referências teóricas e perspectivas metodológicas}

Ao pensarmos na qualidade do emprego, a elaboração de uma perspectiva clínica pode ser comparada, metaforicamente, à construção de uma "caixa de ferramentas", onde é possível articular as contribuições da psicodinâmica do trabalho (Dejours, 1998; Dejours, 1993; Dessors \& Guiho-Bailly, 1998; Molinier, 2008), da clínica da atividade (Clot, 1999, 2008a, 2008b) e da psicossociologia (Amado \& Enriquez, 1994; Barus-Michel et al., 2002; Lhuilier, 2006), com o objetivo de construir quadros conceituais pertinentes à nossa análise.

Quais são as linhas de convergência entre estas "ferramentas”? É possível colocá-las na mesma "caixa"? Em razão de quê? No plano teórico, trata-se, sem dúvida, de uma transgressão, mas trata-se também de experimentar as possibilidades hermenêuticas das categorias conceituais mobilizadas.

Os quadros conceituais que nos propomos a articular em nossa "caixa de ferramentas" compartilham certos traços comuns: em primeiro lugar, a crítica do trabalho contemporâneo e das instituições envolvidas em sua dinâmica, mas também a diferenciação entre trabalho e emprego, que constitui a chave para se compreender a diversidade do mundo do trabalho que integra, ao mesmo tempo, o trabalho "informal", o trabalho voluntário, o empreendedorismo etc. Tomando o partido da crítica do trabalho, vemos que este não se limita à institucionalização econômica, ao emprego. $O$ trabalho é uma atividade guiada por um projeto de transformação do real e de construção de sentido e de significações (Clot \& Lhuilier, 2006). O conceito de real da ergonomia tem aqui um papel muito importante. É na distância entre trabalho prescrito e trabalho real que o sujeito assume o papel de autor de seu próprio trabalho.

Outra questão importante é a ação no trabalho, ou seja, as possibilidades de se criar as condições psicossociais de engajamento na atividade, condições de reflexibilidade e de cooperação no coletivo de trabalho, com o objetivo de enfrentar os problemas que caracterizam a ação coletiva.

Salientamos também a importância do paradigma compreensivo na abordagem da subjetividade e da intersubjetividade. Partimos de uma concepção de sujeito produzido pela história e pela cultura, pelas instituições e pela linguagem, em que a comunicação e a escuta 
são condições para a intercompreensão. Mas é necessário levar em conta a implicação dos sujeitos e do clínico. Os sujeitos são reconhecidos em sua capacidade de agir, de transformar, de criar, de aprender e de transmitir. No plano ético, isso tem consequências consideráveis para a construção da postura e do olhar do clínico: ele tenta, com suas intervenções, contribuir para o aumento do poder de ação dos sujeitos, privilegiando uma coprodução dos conhecimentos em situações reais de trabalho, nas quais é essencial a experiência dos trabalhadores. Nesse sentido, embora se reconheça o sofrimento, o trabalho clínico destaca a dimensão potencialmente emancipadora do trabalho, com base nos recursos criativos e construtivos do sujeito, considerando então o trabalho como atividade subjetivante. A orientação clínica constrói-se a partir do reconhecimento do sofrimento, da escuta que sempre implica riscos, do respeito ao conhecimento que os trabalhadores têm das situações de trabalho. Ela supõe também uma atenção aos conflitos psíquicos e sociais envolvidos, às lutas do coletivo, aos desafios que os trabalhadores devem enfrentar para melhorar suas vidas.

O olhar clínico em ação, no campo da pesquisa ou da intervenção, traz consigo uma abordagem metodológica baseada na análise dos processos em marcha nas situações de trabalho passadas e presentes, com o intuito de reconstruir a qualidade de trabalho tal como é percebida pelos próprios atores. Para tentar uma caracterização dos novos "mundos sociais", é possível usar questionários e entrevistas semiestruturadas, mas busca-se aqui também desenvolver uma abordagem etnográfica. A observação das atividades, das conversas ocasionais e das cenas do cotidiano no trabalho fornece materiais para a construção do corpus que deve ser discutido com os trabalhadores. Aí estão os traços da vida no trabalho a ser explorada coletivamente. De maneira complementar, a entrevista biográfica possibilita explorar, na vida do sujeito, lógicas de ação e as marcas da história e das temporalidades sociais presentes nos relatos (Godard, 1996).

A abordagem biográfica permite não só o acesso à dimensão subjetiva, mas também aos processos culturais e simbólicos, desvelando as relações sociais em suas ancoragens estruturais (Pujol, 2011).

\section{O trabalho em contextos flexíveis: o setor das tecnologias da informação e da comunicação (TIC)}

O setor das tecnologias da informação e da comunicação contribui, na atualidade, para orientar o perfil produtivo da cidade de Córdoba, na Argentina. Graças a seu desenvolvimento, há mais ou menos uma década, essa cidade é reconhecida como "polo tecnológico". O setor IT, historicamente, estava concentrado no entorno de Buenos Aires, mas nos últimos anos tem se estendido significativamente a outras cidades - Rosário, Córdoba e Mendoza (Recalde et al., 2009). Em referência a Córdoba, o acontecimento mais relevante é, sem dúvida, a criação do Cluster Córdoba Technology, em 2001 (López \& Ramos, 2008), que na atualidade abrange 131 empresas locais, em sua maioria do setor TIC. As empresas-membro empregam cerca de 3.500 pessoas, com um volume de negócios de 100 milhões de dólares anuais. A maioria dessas empresas tem menos de 10 anos ( $37 \%$ de 5 a 10 anos, e $28 \%$ de 1 a 5 anos). Além disso, Córdoba dispõe de inúmeros centros universitários de qualidade, dentre os quais seis universidades ligadas à formação de profissionais do setor. Além disso, o desenvolvimento desse setor se reflete na criação de inúmeras empresas intermediárias locais.

Nesse contexto empresarial, e com desemprego "zero", os discursos dos responsáveis políticos, dos empresários e dos consultores descrevem o setor de TIC como "um mundo feliz": esse seria o melhor lugar para trabalhar. Eles também afirmam que a flexibilidade da organização do trabalho é uma oportunidade, já que daria aos trabalhadores maior autonomia e 
chance de desenvolvimento de suas competências, decorrentes dos desafios colocados pela pesquisa constante de performance nas empresas.

$\mathrm{Na}$ Argentina, a modernização da organização do trabalho é um processo em andamento ou, por vezes, limitado a seus aspectos tecnológicos, sem oferecer vantagens para o desenvolvimento pessoal e profissional dos assalariados. Porém, o setor TIC apresenta as formas mais modernas de organização do trabalho. $O$ trabalho organiza-se em redes com equipes de trabalhadores muito bem qualificados. Os operadores dispõem de autonomia para resolver os problemas que aparecem, para enfrentar os acontecimentos, para definir tempos e ritmos de trabalho. Eles têm períodos de trabalho não tradicionais (dias e horas não habituais), com diferentes níveis de complexidade de rotação nos postos (Roitter \& Erbes, 2010). As equipes estão à altura de avaliar seu processo de trabalho e melhorá-lo na ação, graças a decisões operacionais.

Nesse quadro, decidimos aprofundar a compreensão das relações entre a organização do trabalho e a subjetividade dos trabalhadores, utilizando as contribuições da abordagem clínica. Isso implicava substituir as ferramentas metodológicas da coleta de dados e nos servirmos de uma epistemologia de campo própria das ciências histórico-hermenêuticas, com inscrição no paradigma subjetivista.

Para a realização deste estudo, realizamos entrevistas com quinze trabalhadores de diferentes empresas. Todos eles trabalham com desenvolvimento de softwares: analistas funcionais, programadores e operadores de testing. A partir dos relatos, tentamos reconstruir com eles suas trajetórias de trabalho e explorar suas avaliações da qualidade do emprego. Nessa modalidade, o sujeito conta sua "história de vida no trabalho" e a escuta clínica busca captar as expressões do trabalho no real, tal como ele é vivido pelo sujeito.

\section{Flexibilidade do trabalho e subjetividade}

Segundo a opinião dos trabalhadores entrevistados, a partir da chegada das empresas multinacionais, as condições de contratação ultrapassaram amplamente as das empresas locais no que se refere aos salários e ao potencial de desenvolvimento da carreira. As trajetórias profissionais dos entrevistados comportam, em curto prazo, sucessivas mudanças de empresa, o que demonstra grande mobilidade. A maioria dos trabalhadores, principalmente a partir de 2006, tem migrado de empresas locais para empresas estrangeiras.

Os trabalhadores explicam que a mobilidade continua atualmente, graças à demanda crescente, com a chegada de novas empresas associada à falta de recursos humanos suficientes para preencher as demandas. Nesse contexto, as empresas negociam individualmente os contratos de trabalho, visando reter o trabalhador e impedir que ele migre para empresas mais atrativas.

Do ponto de vista das condições contratuais, a qualidade do emprego em outros setores produtivos é fruto de uma longa tradição de produção local baseada em uma reserva de competências endógenas reatualizadas, a partir do aumento da produção e dos empregos, e da revitalização do mercado de trabalho e de suas instituições. No setor informático, no contexto de expansão e consolidação dessas empresas, a qualidade é definida pela necessidade de reter o pessoal, o que favorece as possibilidades de negociação "individual" com os trabalhadores. Estes são, em sua maioria, profissionais universitários. Essa individualização das condições de emprego favorece também a subutilização dos trabalhadores e a ocorrência de grande discrepância entre as competências pessoais e os salários. 
Baseando-se no saber dos trabalhadores, as empresas privilegiam formas flexíveis de organização, que fazem parte do modelo de autorregulação do trabalho e impõem aos trabalhadores novas exigências em função dos serviços e produtos que comercializam. Ao mesmo tempo, exige-se um conjunto de competências clássicas, bem como de novos conhecimentos e novas práticas. Os trabalhadores devem ser capazes de interpretar as exigências operacionais e identificar as soluções técnicas ad hoc: em algumas empresas o essencial não é a ferramenta mais avançada, é preciso escolher a técnica mais adaptada para o problema a ser resolvido. Por outro lado, em outros processos, o domínio das tecnologias de ponta é fundamental para a resolução dos negócios (Pujol, 2005).

Em algumas organizações, essas estratégias de produção e de gestão geram contradições entre a negociação individual dos contratos de trabalho e a necessidade de um sistema de remunerações equitativo. Os regimes salariais são pouco equiparados e pouco transparentes. Observam-se acentuadas diferenças nas condições de contratação de pessoas com tarefas e competências similares. Nesse contexto, a formação de equipes de trabalho autogestionário, a aprendizagem, a inovação e a cooperação coletiva tornam-se questões muito difíceis para se tratar. Uma entrevistada assim se refere a esse assunto: "No começo, fui alvo do ressentimento e da raiva de alguns colegas, pelo fato de eu ser nova e ter um melhor salário. Como eles não podem se vingar da empresa, eles o fazem em cima do novo empregado. Por isso, não é fácil trabalhar junto...”.

A negociação individual tem como base principal o grau de domínio de tecnologias pelos trabalhadores. Isso lhes impõe altas exigências de atualização profissional, invadindo suas vidas pessoais. Para atualizar seus conhecimentos, é frequente os trabalhadores se dedicarem a muitas horas de autoformação fora do expediente de trabalho. Todos eles afirmam que a atividade de programação demanda um aprendizado permanente. E, mesmo que a oferta de cursos de capacitação seja constante, em quase todas as empresas, a autoformação continua muito necessária. Esta é ao mesmo tempo uma fonte de prazer no trabalho e uma autoexigência: trata-se de um fator-chave nesse campo. Como exemplo, observemos a fala de um programador entrevistado:

[...] eu tinha de desenvolver um novo projeto, sobre o qual eu jamais tinha trabalhado, e contava apenas com duas semanas para terminá-lo. As tarefas eram, então, ler, buscar as referências, fazer um esforço para "salvar" o projeto. Eu aprendi, mas com muita pressão do tempo e muito deprimido também. A gente precisa estar atualizado para ser competitivo, porque se o seu produto não estiver em dia... vem outro produto e também outro trabalhador para substituir você.

$\mathrm{Na}$ hora de identificar os aspectos do trabalho que produzem grande satisfação, a maioria dos trabalhadores assinala que a capacidade de criar e superar os problemas que enfrentam no dia a dia é uma das dimensões mais gratificantes do trabalho. Um dos programadores declarou: "eu me sinto orgulhoso, quando termino em tempo e mais ainda quando eu não tinha, a princípio, nenhuma ideia de como desenvolver a tarefa". Nesse exemplo, percebe-se, de acordo com Clot (2009), a relevância dos critérios de eficácia como fonte de prazer para os trabalhadores, quando eles estão ligados ao sentido que o sujeito dá à sua atividade.

Nas entrevistas, todos os trabalhadores falaram do frágil controle sobre a execução das tarefas e sobre tudo que diz respeito aos horários e à disciplina, o que é frequente no modelo flexível que caracteriza o setor. No entanto, apesar de o controle em algumas empresas ser percebido como frouxo, o grau de compromisso e responsabilidade está fortemente presente: "[...] não percebemos a pressão atrás de nós, alguém nos dizendo, por exemplo, façam horasextras [...] a pressão vem de nós mesmos, do fato de nos vermos todos os dias e de nos dizermos: pois é, vamos lá! É disso que gostamos! Porque se você faz algo bom para o benefício da empresa, você é útil, a empresa cresce e você também". 
Como expressam Falzon e Sauvagnac (2009), nas indústrias do setor TIC, em que o trabalho é definido em termos de missões a cumprir, nenhuma exigência explícita conduz o trabalhador a essa "auto" exigência. Segundo os trabalhadores, "a tarefa é de lançar o projeto, pouco importa como fazê-lo, se precisamos de mais horas, a gente trabalha mais, quando a gente se compromete com um prazo... se não, ao primeiro sinal de alerta, os chefes vão falar com o cliente".

Marie-Anne Dujarier (2010) afirma que as organizações demandam sempre mais de seus empregados. Ela descreve a produção de prescrições que exigem o ideal e a conformidade a ele. O "desvio" é socialmente punido, o que leva cada sujeito a simular a conformidade com esse ideal e a dissimular o trabalho real. A prescrição do ideal instaura um universo de exigências ilimitadas, em que cada qual é sempre culpado por não produzir mais. Nesse modelo, as obrigações são tácitas, infinitas e instáveis.

Outro ponto forte das entrevistas realizadas refere-se à autonomia que caracteriza o trabalho nessas grandes empresas, a autogestão das tarefas e a formação. Na maioria delas, a supervisão não segue formas definidas de controle, o que vale também para a formação de recursos humanos. Elas buscam sobretudo assegurar a disponibilidade das ferramentas, incentivar a participação e a autogestão da conformidade associada às responsabilidades de cada um, bem como a resolução dos problemas das equipes: "em relação aos problemas, devemos garantir que eles sejam resolvidos e avaliar seu impacto. A solução dos problemas é responsabilidade do grupo e deve supor, no mínimo, uma discussão em grupo. Às vezes a gente não tem tempo suficiente para isso. Cada qual está ocupado com sua respectiva tarefa, então a gente tem de resolver o problema individualmente". Observe-se que esse estilo de gestão não é comum a todas as empresas. Muitas delas mantêm o estilo de supervisão baseado em forte prescrição de tarefas e no controle da realização das mesmas.

A maioria dos trabalhadores entrevistados enfatiza que a exigência cognitiva das tarefas é muito alta e requer muitos esforços: "você não pode ir trabalhar com a ideia de que não precisa pensar". Outro entrevistado diz: "eu não penso que posso continuar assim durante 10 ou 15 anos [...] às vezes, à noite, continuo pensando nas tarefas e é difícil conciliar o sono". Nesta situação, as pessoas afirmam que, em certas empresas, as equipes de trabalho são levadas a desenvolver modos de cooperação. Essa exigência de cooperação torna-se uma das principais regras do ofício: "você repara na carga de trabalho de todos, e se alguém está mais liberado, ele deve realizar outras tarefas para aliviar os colegas". Em outras organizações, as dinâmicas coletivas são diferentes. As injustiças produzidas pela desigualdade das condições de emprego impedem que os trabalhadores ajam coletivamente diante das exigências do trabalho. E isso prejudica o engajamento na atividade: "há pessoas que ficam com raiva dos colegas, enquanto outras não se preocupam e pensam: 'se quiserem, podem me demitir'. Outras dizem: 'se eles não aumentam meu salário, nem me desgasto com isso'; outros ainda dormem no trabalho, especialmente à noite".

Assim, da mesma maneira que a aprendizagem permanente é valorizada, a mobilização subjetiva cristalizada nas contribuições significativas dos trabalhadores é estimulada em algumas organizações e valorizada por diferentes meios (Barnes, 2010).

O reconhecimento dos pares e dos superiores é apresentado por Dejours (1998) como um recurso imprescindível para a preservação da saúde e para a construção da identidade profissional. Algumas organizações tendem a incentivar formas de reconhecimento, utilizando disposições que lembram as "recompensas" ou distinções escolares: "quando alguém se destaca, você conhece sua contribuição através de uma estrela. As estrelas são dadas em função da ética, do compromisso, da inovação, do prazer e da excelência. São estrelas dadas entre colegas", revela um programador a respeito da prática adotada na empresa em que ele trabalha. Mas a dinâmica de reconhecimento inscreve-se mais fundamentalmente e mais naturalmente nas trocas informais, que se desenvolvem no cotidiano laboral, nas interações internas das 
equipes. Isso contribui para a cooperação entre colegas, apesar das desigualdades nos salários e nas vantagens sociais.

Os trabalhadores se surpreendem quando lhes perguntamos sobre o sindicato: eles tendem a "naturalizar" o fato de não terem um sindicato e consideram normal ter de negociar individualmente suas condições de trabalho. O setor é ainda pouco institucionalizado e há pouco progresso em matéria de direitos trabalhistas. Ao narrar suas trajetórias profissionais, as pessoas identificam as empresas em que existem melhores condições de trabalho e aquelas em que passaram por sofrimento, mas não relacionam essas observações com a possibilidade de ações coletivas.

Sobre isso, é importante salientar que a valorização do aperfeiçoamento profissional na área da informática sempre foi privilegiada pelas categorias sociais médias e altas, que integram alguns traços idiossincráticos à caracterização do mercado de trabalho. Isso remete, por exemplo, à prioridade dada pelos profissionais jovens à sua integração nas empresas: eles adquirem sua formação técnica após a universidade, pois não possuem experiência de trabalho antes da graduação. Percebem as grandes empresas como as zonas de empregabilidade desejadas e revelam pouco interesse pela questão sindical.

\section{Conclusão}

Este estudo permite analisar as experiências e as representações dos trabalhadores de um setor da produção de forte intensidade em conhecimento: a indústria de desenvolvimento de softwares. Nesse campo, a organização do trabalho apresenta algumas particularidades que o diferenciam claramente da produção tradicional.

As principais conclusões desta pesquisa-ação remetem às avaliações que os trabalhadores fazem de seu trabalho. Elas exploram as características do trabalho flexível: autogestão, enriquecimento cognitivo, cooperação nas equipes de trabalho, participação nas equipes e envolvimento com o trabalho. No entanto, trata-se de um setor não tradicional, sem regras técnicas estabilizadas, sem gênero profissional estabelecido (Clot, 2008a), sem mecanismos de representação sindical. Ademais, a precariedade das condições de trabalho e os efeitos de seu modo de organização não têm outros limites além das possibilidades fisiológicas e psicológicas do sujeito. Existe, por isso, uma relação muito significativa entre a demanda de emprego, as exigências das tarefas, a concorrência que se estabelece entre os trabalhadores e as consequências disso em sua saúde e em sua vulnerabilidade.

Os relatos dos atores mostram que a organização do trabalho é um fator-chave na qualidade do emprego. $\mathrm{O}$ trabalho em rede, com grupos autogeridos e tarefas organizadas em torno de um projeto, engendra formas de trabalho flexíveis. A prescrição limita-se aos objetivos e não integra os modos operatórios. Essas características são justamente as que possibilitam um desenvolvimento significativo dos profissionais que devem enfrentar o desafio permanente da solução de problemas; mas, ao mesmo tempo, isso tem um impacto negativo na subjetividade e na saúde. A necessidade de atingir objetivos com prazos fixos, com escassos recursos organizacionais, leva os trabalhadores a se impor exigências significativas, seja na duração da jornada de trabalho, que se estende à sua casa, seja na responsabilidade pela própria formação profissional e na corresponsabilidade com seus pares em relação aos resultados obtidos.

Outra questão-chave com a qual nos deparamos diz respeito à representação sindical ou à falta dela. O setor de TIC é marcado por um processo de individualização do trabalho e pela ausência de representação sindical. As condições de "desemprego zero" do setor (ligadas à ausência de tradições no setor, às características sociodemográficas desses trabalhadores e a 
outros fatores) impedem que seus profissionais se reconheçam como membros de um grupo que deveria garantir, por meio da representação sindical, que a especificidade de seu trabalho e de sua condição coletiva seja vista como interesse de seu ofício.

\section{Referências}

Amado, G. \& Enriquez, E. (1994). Positions de la psychosociologie. Revue Internationale de Psychosociologie, 1 (1), 3 4.

Barnes, F. (2010). El ambiente organizacional calificante en empresas del sector de software y servicios informáticos de la ciudad de Córdoba. XV Reunión Anual De La Red Pymes Mercosur. Mendoza, Argentina.

Barros, R. \& Mendoza, R. (1999). Una evaluación de la calidad del empleo en Brasil 1982-1996. In R. Infante (Org.), La calidad del empleo. La experiencia de los países latinoamericanos y de los Estados Unidos. Lima: OIT.

Barus-Michel, J., Enriquez, E. \& Levy, A. (2002). Vocabulaire de psychosociologie. Références et positions. Toulouse: Érès.

Bisang, R., Novick, M., Sztulwark, S. \& Yoguel, G. (2005). Las redes de producción y el empleo. Elementos básicos para la formulación de políticas públicas. In M. Casalet, M. Cimoli \& G. Yoguel (Orgs.), Redes, Jerarquías y dinámicas productivas (pp. 153-201). Buenos Aires: Miño y Dávila / Flacso / OIT.

Clot, Y. (1999). La fonction psychologique du travail. Paris: PUF.

Clot, Y. (2008a). Travail et pouvoir d'agir. Paris: PUF.

Clot, Y. (2008b). Le travail sans homme? Pour une psychologie des milleux de travail et de vie. Paris: La Découverte.

Clot, Y. \& Lhuilier, L. (2006). Perspectives en clinique du travail. Nouvelle Revue de Psychosociologie, 1, 179-193.

Curie, J. (2005). Cinquante ans de Psychologie du Travail. Bruxelles: Institut des sciences du travail de l'Université Libre de Bruxelles.

Dejours, C. (1993). Intelligence pratique et sagesse pratique: deux dimensions méconnues du travail réel. Éducation permanente, 116, 131-196.

Dejours, C. (1998). El factor humano. Buenos Aires: Piette/Conicet.

Dessors, D. \& Ghuio-Bailly, M.-P. (1998). Organización del trabajo y salud. De la psicopatología a la psicodinámica del trabajo. Buenos Aires: Asociación Trabajo y Sociedad - PIETTE (CONICET).

Dujarier, M. (2010). El ideal en el trabajo. Madrid: Modus Laborandi.

Falzon, P. \& Sauvagnac, C. (2009). Carga de trabajo y estrés. In P. Falzon (Org.), Manual de ergonomia (pp. 165 181). Madrid: Modus Laborandi.

Farné, S. (2003). Estudio sobre la calidad del empleo en Colombia. Oficina Regional.

Godard, F. (1996). El debate y la práctica sobre el uso de las historias de vida en las Ciencias Sociales. In F. C. Godard (Org.), Uso de las historias de vida en las Ciencias Sociales (pp. 5-55). Bogotá: Cuadernos del CIDS.

Infante, R. \& Vega Centeno, M. (1999). La calidad del empleo: lecciones y tareas. In R. Infante \& R. Infante (Orgs.), La calidad del empleo. La experiencia de los países latinoamericanos y de los Estados Unidos. Lima: OIT.

López, A. \& Ramos, D. (2008). La industria de software y servicios informáticos argentina. Tendencias, factores de competitividad y clusters. Buenos Aires: Flasco.

Mocelin, D. (2008). ¿Del trabajo precario al trabajo decente? La calidad de empleo como perspectiva analítica. VI Congreso Internacional de las Américas. Buenos Aires: Versión preliminar.

Molinier, P. (2008). Les enjeux psychiques du travail. Introduction à la psychodinamique du travail. Paris: Payot et Rivages.

Pujol, A. (2005). Empleo, calificaciones y competencias de los trabajadores informáticos: algunas consideraciones criticas frente a los nuevos escenarios del sector. Actas del IV Coloquio Internacional "Las transformaciones de la modernidad excluyente y las políticas sociales”. Instituto de Investigación y Formación en Administración Pública de la Universidad Nacional de Córdoba. Córdoba, Argentina.

Recalde, A., Marí, M., Carri, R., Baum, G. \& Artopoulos, A. (2009). Libro blanco de la prospectiva TIC, Proyecto 2020. Buenos Aires: Ministerio de Ciencia, Tecnología e Innovación Productiva. 
Roitter, S. \& Erbes, A. (2010). La organización del trabajo en empresas de servicios: un análisis desde la perspectiva de los trabajadores. 15a Reunión Anual de la Red PyMEs Mercosur. Mendoza, Argentina.

Slaughter, J. (1998). La producción depurada y los buenos empleos. In OIT (Org.), Trabajo, reestructuración, integración y mercado laboral. Crecimiento y calidad de empleos en economías abiertas. OIT.

Valenzuela, M. \& Reinecke, G. (2000), ¿Más y mejores empleos para las mujeres? La experiencia de los países del Mercosur y Chile. Santiago de Chile: OIT.

Vanbastelaer, A. \& Hussmann, R. (2000). Measurement of the quality of employment: introduction and overview. Genebra: Joint ECE-Eurostat-Ilo Seminar on Measurement of the Quality of Employment.

\section{Endereço para correspondência}

apujol@psyche.unc.edu.ar 